\title{
Risperidone was effective for a first psychotic episode
}

Emsley RA and the Risperidone Working Group. Risperidone in the treatment of first-episode psychotic patients: a double-blind multicenter study. Schizophr Bull 1999;25:721-9.

QUESTION: In patients with a first psychotic episode, what is the effectiveness of risperidone compared with haloperidol for clinical improvement and extrapyramidal symptoms (EPSs)?

\section{Design}

6 week randomised \{allocation concealed*\}†, blinded $\{$ clinicians and patients $\}, *+$ controlled trial.

\section{Setting}

61 psychiatric centres in Australia, Belgium, Canada, France, Germany, Korea, the Netherlands, South Africa, Sweden, and the UK.

\section{Patients}

183 patients who were $15-45$ years of age (median age 25 y, $67 \%$ men) and had a DSM-III-R diagnosis of provisional schizophreniform disorder or schizophrenia, psychotic symptoms requiring treatment with an oral antipsychotic agent, receipt of $\leq 3$ days of emergency treatment for this disorder, and no clinically relevant abnormalities. Exclusion criteria were pregnancy, potential for pregnancy, or lactation; other mental illness; psychoactive substance abuse; previous depot antipsychotic treatment; clinically important organic disease; or participation in clinical trials of study drugs in the previous 4 weeks. 137 patients $(75 \%)$ completed the study; all patients were included in the intention to treat analysis.

\section{Intervention}

Patients were allocated to $2 \mathrm{mg}$ twice daily of risperidone $(n=99)$ or haloperidol $(n=84)$. The doses could be increased to a maximum of $8 \mathrm{mg}$ twice daily.

\section{Main outcome measures}

Treatment efficacy assessed by the Positive and Negative Syndrome Scale (PANSS), the Clinical Global Impression (CGI) scale, and the Brief Psychiatric Rating Scale (BPRS). Clinical improvement was defined as a $\geq 50 \%$ reduction in total PANSS and BPRS scores. EPSs were assessed using the Extrapyramidal Symptom Rating Scale (ESRS).

\section{Main results}

PANSS and BPRS total scores were improved from baseline in both risperidone and haloperidol groups $(\mathrm{p}<0.001)$; no differences existed between the groups. The groups did not differ for proportion of patients who were clinically improved on PANSS scores $(p=0.19)$ or BPRS scores $(p=0.08)$ or who completed the study (table). Greater decreases from baseline occurred in patients who received haloperidol on ESRS scores for hyperkinesia factor $(\mathrm{p}=0.007)$ and total ESRS (parkinsonism, dystonia, and dyskinesia) $(\mathrm{p}=0.046)$. More haloperidol recipients than risperidone recipients required antiparkinsonian medications $(\mathrm{p}<0.001)$ (table).

\section{Conclusion}

In patients with a first psychotic episode, risperidone was as effective as haloperidol for relieving psychotic symptoms and caused fewer extrapyramidal symptoms.

*See glossary.

$\dagger$ Information provided by author.

\section{COMMENTARY}

The study by Emsley et al is the only published international multicentre study that examines the use of risperidone in patients with a first psychotic episode. Given that the study was done in 61 centres in 10 countries, it is likely that the results will apply to a wide variety of clinical settings. It adds substantially to the data already available on this compound for the treatment of schizophrenia, and addresses 2 important clinical issues. An important feature of this study is that lower doses of haloperidol were used than have been used in other trials-the maximum dose was limited to $16 \mathrm{mg}$ /day.

The study finds that risperidone is not more effective than haloperidol in first episode patients. This finding is important because some clinicians now suggest that it may be an appropriate first line treatment. The study found that risperidone was less likely to cause EPSs than haloperidol, an advantage that might lead to greater levels of compliance with this medication. No clear difference was seen, however, in overall dropout rates and no direct evidence exists that fewer initial side effects translate into greater compliance later in the course of an illness. Although the mean daily dose of haloperidol at endpoint was $5.6 \mathrm{mg}$, higher doses (up to $10 \mathrm{mg}$ twice/d) could be used earlier in the study. Although haloperidol is known for its high propensity to cause EPSs even at low doses, the higher earlier dosing may have exaggerated the difference between the 2 drugs in favour of risperidone. Whether, on the basis of fewer EPSs, risperidone is justified as first line treatment will depend on the difference in total side effect burden at appropriate doses. Further replication of this study finding and consideration of cost effectiveness are needed before risperidone can be recommended for the routine first line treatment of first episode schizophrenia. Andrew McIntosh, BSc, MB, ChB, MRCPsych Royal Edinburgh Hospital Edinburgh, UK

1 Kennedy E, Song F, Hunter R, et al. Cochrane Review, latest version 25 August 1998. In: Cochrane Library. Oxford: Update Software.

2 Taylor D, McConnell D, McConnell Habel K, et al. The Bethlam and Maudsley NHS Trust 1999 prescribing guidelines. 5th edition. London: Dunitz, 1999.
Source of funding: Jannsen Cilag.

For correspondence: Dr R A Emsley, Department of Psychiatry, University of Stellenbosch, Tygerberg 7505, Cape Town, South Africa. Fax +2721933 6159 .

Risperidone v haloperidol for a first psychotic episode at 6 weeks

\begin{tabular}{|c|c|c|c|c|}
\hline Outcomes & Risperidone & Haloperidol & RBI $(95 \% \mathrm{Cl})$ & NNT \\
\hline $\begin{array}{l}\text { Clinically improved } \\
\text { (PANSS) }\end{array}$ & $63 \%$ & $56 \%$ & $12 \%(-12$ to 44$)$ & $\begin{array}{l}\text { Not } \\
\text { significant }\end{array}$ \\
\hline $\begin{array}{l}\text { Clinically improved } \\
\text { (BPRS) }\end{array}$ & $65 \%$ & $55 \%$ & $18 \%(-7$ to 52$)$ & $\begin{array}{l}\text { Not } \\
\text { significant }\end{array}$ \\
\hline Completed study & $80 \%$ & $69 \%$ & $16 \%(-2.5$ to 39$)$ & $\begin{array}{l}\text { Not } \\
\text { significant }\end{array}$ \\
\hline & & & RRR (Cl) & NNT (Cl) \\
\hline $\begin{array}{l}\text { Need for } \\
\text { antiparkinsonian } \\
\text { drugs }\end{array}$ & $50 \%$ & $75 \%$ & $33 \%(16$ to 47$)$ & 5 (3 to 10$)$ \\
\hline
\end{tabular}

defined in glossary; RBI, RRR, NNT, and $\mathrm{Cl}$ calculated from data provided by author. 